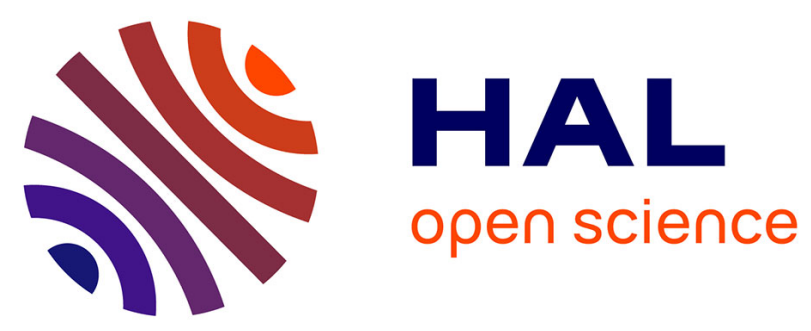

\title{
The Impact of Game Elements on Learner Motivation: Influence of Initial Motivation and Player Profile
} Stéphanie Reyssier, Stuart Hallifax, Audrey Serna, Jean-Charles Marty, Stephane Simonian, Elise Lavoué

\section{- To cite this version:}

Stéphanie Reyssier, Stuart Hallifax, Audrey Serna, Jean-Charles Marty, Stephane Simonian, et al.. The Impact of Game Elements on Learner Motivation: Influence of Initial Motivation and Player Profile. IEEE Transactions on Learning Technologies, 2022, 15 (1), 10.1109/TLT.2022.3153239 . hal-03579428v2

\author{
HAL Id: hal-03579428 \\ https://hal.univ-lyon2.fr/hal-03579428v2
}

Submitted on 20 Feb 2023

HAL is a multi-disciplinary open access archive for the deposit and dissemination of scientific research documents, whether they are published or not. The documents may come from teaching and research institutions in France or abroad, or from public or private research centers.
L'archive ouverte pluridisciplinaire HAL, est destinée au dépôt et à la diffusion de documents scientifiques de niveau recherche, publiés ou non, émanant des établissements d'enseignement et de recherche français ou étrangers, des laboratoires publics ou privés. 


\title{
The Impact of Game Elements on Learner Motivation: Influence of Initial Motivation and Player Profile
}

\author{
S. Reyssier, ECP, University of Lyon, S. Hallifax, LIRIS, University of Lyon, A. Serna, LIRIS, INSA \\ Lyon, J.-C. Marty, LIRIS, University of Lyon, S. Simonian, ECP, University of Lyon, and É. Lavoué, \\ University Jean Moulin Lyon 3, iaelyon School of Management, LIRIS, University of Lyon
}

\begin{abstract}
Several studies have been conducted in recent years into the effects of gamification on learner motivation. However, little is known about how learner profiles affect the impact of specific game elements. This research analyzes the effect of a gamified mathematic learning environment on the motivation and the motivated behaviors of $\mathbf{2 5 8}$ learners in secondary schools in France. Overall, results indicate that randomly assigned game elements generally demotivate learners. A more thorough analysis revealed that gamification has a positive impact on the most amotivated learners to do mathematic, although different effects were observed on learners. In particular, we noticed significant influences of their initial level of motivation and their player type on the variation in motivation during the study. We show that these influences vary according to the game element they used. These findings suggest that to increase efficiency, gamification should be tailored not only to the player profile but also to their level of initial motivation for the learning task.
\end{abstract}

Index Terms - Interactive learning environment, Gamification, Learner motivation, Player types.

\section{INTRODUCTION}

$\mathrm{I}^{\mathrm{I}}$ $\mathrm{n}$ the last decade, gamification, which is commonly defined as the use of game design elements within non-game contexts [1], has promised to enhance human motivation and engagement in different contexts such as education [2]-[4], health [5], [6], and the workplace [7]-[9]. In education, Kapp [10]-[11] argues that gamification serves several purposes such as making learning easier from a cognitive and emotional point of view, enabling automatic feedback, personalizing and individualizing learning, and changing behaviors, but above all,

Manuscript received September 16, 2020; revised February 26, 2021; accepted . Date of publication; date of current version. This work was supported in part by the E-FRAN project, in part by the Caisse des Dépôts. (Corresponding authors: Reyssier, S.; Hallifax, S.; Serna, A.; Marty, J.-C.; Simonian, S.; Lavoué, E).

S. Reyssier is with the Laboratory Éducation, Cultures, Politiques, University of Lyon, 69007 LYON (e-mail: stephanie.reyssier@univ-lyon2.fr).

S. Hallifax was with the Laboratoire d'InfoRmatique en Images et Systèmes

d'information, University of Lyon, 69007 LYON. He is now with the

Stratford School of Interaction Design and Business and the School of

Computer Science, University of Waterloo, ON N2L 3G1, CANADA (e-mail: stuart.hallifax@uwaterloo.ca).

A. Serna is with Laboratoire d'InfoRmatique en Images et Systèmes d'information, INSA Lyon, 69100 VILLEURBANNE (e-mail: Audrey.serna@insa-lyon.fr). encouraging learner engagement in the task, thus making learners more active in their learning.

According to Nacke and Deterding [12], the first studies in gamified education were essentially focused on the effect of a set of game elements on users, which did not enable identification of the impact of each game element taken separately. These studies did not consider the individual characteristics of learners, which can account for the different and sometimes contradictory impacts of gamification observed on learner motivation and engagement [13]-[14].

Several studies focus on the relationships between user player type and game elements or game mechanics [15]-[18]. Generally, we adapt by assigning users to specific categories and by providing different game elements for each category. "Player type" represent a user's preference for video games. For instance, the Hexad [17] typology distinguishes six player types (Players, Socializers, Free Spirits, Achievers, Philanthropists, and Disruptors), and users are categorized into whichever type they score highest. We can also consider all of the users' scores for each player type, thus creating their "player profile." Some studies also consider that motivation can greatly affect the effects of gamification [4]. However, no study has yet considered these two aspects when evaluating the impact of different game elements on learner motivation.

In this paper, we propose to study the impact of gamification according to both learner initial motivation and player profile. For this, we ran a large-scale field study in four secondary schools in France. 258 learners used a gamified mathematiclearning environment in their habitual classroom activities,

J.C. Marty is with Laboratoire d'InfoRmatique en Images et Systèmes d'information, University of Savoie-Mont Blanc, 73000 CHAMBERY (email : Jean-charles.marty@univ-smb.fr).

S. Simonian is with the Laboratory Education, Cultures, Politiques, Université of Lyon, 69007 LYON (e-mail: stephane.simonian@univ-lyon2.fr).

É. Lavoué is with the Laboratoire d'InfoRmatique en Images et Systèmes d'information, Université of Lyon, 69007 LYON (e-mail : elise.lavoue@,univlyon3.fr). 
$>$ REPLACE THIS LINE WITH YOUR MANUSCRIPT ID NUMBER (DOUBLE-CLICK HERE TO EDIT) <

representing ten lessons and 45 exercises in literal calculation. We then analyzed their usage data in order to determine the impact of six game elements (score, badges, avatar, ranking, progress, and timer). Each learner received randomly one of these game elements, allowing the impact of game elements to be studied according to learner initial motivation and player profile.

The results of this study show that the gamification approach generally demotivates learners. A more thorough analysis revealed that gamification, although it might have positive impacts on the motivation of learners who were initially less motivated, might also have a negative impact on the most motivated ones. Also, the impact of each game element on learner motivation varies according to their initial level of intrinsic motivation, extrinsic motivation, and amotivation. This impact may also depend on player types. In general, we recommend Avatar for learners with a high initial amotivation or with a high Player score. We recommend Badges for Disruptors and for learners who are initially intrinsically motivated for mathematic. We recommend Progress for learners with a high initial amotivation. We recommend Ranking for high Free Spirit learners. We recommend Score for learners with a high initial intrinsic motivation but who are also strong Socializers. We recommend Timer for learners with high initial amotivation or high Achiever or Free Spirit scores.

These results highlight the necessity to tailor gamification, considering both player types and learner initial motivationsomething that has been recently investigated in the field of pro-environmental behavior by Vanhoudt et al. [19]. Finally, we provide design recommendations on the game elements to use in education according to these two factors.

\section{RELATED WORK}

\section{A. Effects of Gamification on Learners}

Theoretical foundations of research into the effects of gamification on user motivation are mainly based on the selfdetermination Theory (SDT) [20], which argues that human beings are intrinsically motivated to engage in activities that satisfy three basic psychological needs: competence (sense of efficacy), autonomy (volition and personal agency), and relatedness (social connectedness). SDT also argues that humans strive to fulfil these needs in order to enhance wellbeing. This theory is concerned with how individuals regulate themselves to a greater or lesser extent depending on external constraints. It explains why subjects are more or less selfdetermined, and whether their motivations to act are intrinsic and linked to the notion of pleasure or extrinsic and linked to external contingencies (cognitive evaluation theory). In particular, it has been established that rewards degrade intrinsic motivation, and particularly those that act as controlling factors. Meaningful gamification should spontaneously provoke the satisfaction of these three user needs [21], especially the sense of competence [1], and so enhance learner motivation. However, as we will show in this section, the effects of gamification on learner motivation are somewhat varied, and often contradictory.
Hamari [22] showed that badges motivated users to increase their activity in a trading/sharing app. Landers et al. [13] demonstrated the effectiveness of leaderboards for simple tasks, where they served as a goal setting tool for users. However, their effectiveness dropped off as task difficulty increased. Sailer et al. [23] tested two gamified situations in their order picking simulation to motivate and engage participants with the task: one using badges, leaderboards, and performance graphs, and another using avatars, meaningful stories, and teammates. They found that the first condition positively affected the satisfaction of their competence needs and increased feelings of task meaningfulness in participants. The second condition increased feelings of social relatedness and relevance.

Regarding more particularly the educational domain, Filsecker and Hickey [24] tested the effects of external rewards on motivation and engagement in fifth graders. They expected that the inclusion of external rewards would decrease intrinsic motivation in their learners. They found that, by including these rewards in a gameful-like manner, they could avoid the expected decrease in intrinsic motivation and even increase learner conceptual understanding of the studied topic. Kyewski and Kramer [25] obtained more nuanced results when testing badges in three different conditions (visible only by the learner, visible to everyone, and no badges). They found that their badges had less impact on learner motivation and performance than they had initially assumed. Those badges, only visible by the learner, were better evaluated than those that were visible by everyone. In addition, in a study on how gamification affects online learning discussion, Ding et al. [26] showed that learners were more interested in the game elements directly linked to their grades. Learners showed greater controlled motivation (motivated by grades and instructor opinion) than autonomous motivation (intrinsically motivated for learning). Also, Denny et al. [3] tested the effect of badges and scores on learner behavior. They found that only badges had an effect on how participants behaved in their experiment, increasing the number of self-assessments made. They also found that this directly resulted in better examination performance for those participants.

Several studies compare the impact of gamified and nongamified learning environments. For instance, Zainuddin et al. [27] tested two versions of a flipped class setting: one with gamification (points, badges, and leaderboards) and one without. They found that learners provided with the gamified environment had increased levels of perceived competence, autonomy, and relatedness, better performance, and were able to achieve better results during the tests. On the contrary, Monterrat et al. [28] showed that learners who were free to use a non-gamified learning environment had a higher level of intrinsic motivation after the experimentation, compared to learners using a gamified environment. Finally, Jagust et al. [29] tested two adaptive situations. In the first situation, the time learners had to answer questions changed depending on how quickly they answered the previous question. In the second situation, a target score changed depending on group performance. In both situations, learners completed more tasks 
$>$ REPLACE THIS LINE WITH YOUR MANUSCRIPT ID NUMBER (DOUBLE-CLICK HERE TO EDIT) $<$

than in a non-gamified situation, where the first situation had a greater effect.

These results tend to show that there is no consensus on the effect of gamification on learner motivation and that this effect may vary according to the type of game elements used. This is echoed, for example, in the study presented by Van Roy and Zaman [30], who tested how a gamified system designed to support students' needs affected their motivation. They showed that "the effects are highly personal and can differ widely between different learners." A recent literature review of gamification research by Koivisto and Hamari [31] also points out that "while the results in general lean towards positive findings ... the amount of mixed results is remarkable".

\section{B. Learner Characteristics Influencing the Effect of Gamification}

Many studies investigate the effects of tailored gamification on user motivation depending on different user characteristics. For instance, Orji et al. [32] showed that the different motivational strategies implemented in game elements affect different categories of users based on their BrainHex player type [15] (archetypal reasons for which users play and are motivated to play games). Recently, Hallifax et al. [41] ran a crowdsourced study to explore factors that should be considered for tailored gamification. They tested 12 different game elements in a contextless setting and compared their results to those in various studies from the related literature (in educational, health, and sport settings). They showed that the choice of player profile and the user activity or domain have a major impact on how gamification affects user motivation, as many of their findings from this contextless setting are different from those found in the specific contexts. They also showed that the Hexad [17] player profile is the most appropriate for tailored gamification.

Several studies were conducted in the educational domain. For instance, Roosta et al. [33] presented learners with different game elements based on their "motivation type." They used a questionnaire called the Elliot Achievement Goal Questionnaire, which provides an assessment of users' achievement motivations. Learners used an online tool for one month. The authors found that learners, who had game elements suited to their motivation type, showed significant differences in motivation, engagement, and quiz results compared to learners who had randomly assigned game elements. They used learner participation rates in the online activities as a metric to gauge motivation and engagement. Kickmeier-Rust et al. [34] ran a study where learners used an adaptive gamified system over two sessions to learn divisions. The system was adapted to learner behavior (the amount and number of mistakes made by learners) by tailoring the game element feedback. According to the authors, the personalized system reduced the amount of errors that learners made. Learners using the adaptive situation showed a greater decrease in errors made in the second session than learners who used the nonadaptive situation.

Other studies based their adaptation on the learner player type. Mora et al. [35] reported a general positive impact from their adaptation based on the Hexad profile, with an increase in behavioral and emotional motivation in learners who used a personalized gamified collaborative problem-solving tool. Lavoué et al. [4] also showed that, amongst the most engaged learners, those with adapted game elements depending on their player profile (BrainHex typology) spent more time on the online learning environment.

All these studies highlight the need to consider learner characteristics, such as player type and initial motivation, when providing learners with game elements. In line with these studies, the aim of this paper is to understand how learner player type and initial motivation influence the impact of specific game elements on their motivation.

\section{RESEARCh QUESTIONS}

In our study, we propose to answer the following questions:

--RQ1 How does gamification affect learner motivation? We studied the variation in learner motivation from the beginning to the end of the course. We split learners into subgroups based on which game element they used in order to evaluate how each game element affected their motivation, as well as the number of motivated behaviors generated.

--RQ2 How do individual learner characteristics influence the impact of each game element on their motivation? We more particularly studied the influence of player profile types and the initial level of motivation scores on the variation in motivation, as well as the motivated behaviors they generated.

\section{LEARNING ENVIRONMENT}

The participants used a gamified version of the Moodle learning management system called "LudiMoodle" (see Fig. 1), that was developed for the project. In total, it proposes six different game elements, designed in collaboration with the teachers involved in the project and improved thanks to learner feedback. The six game elements used are described in Section IV. B: Avatar, Badges, Progress, Ranking, Score, and Timer.

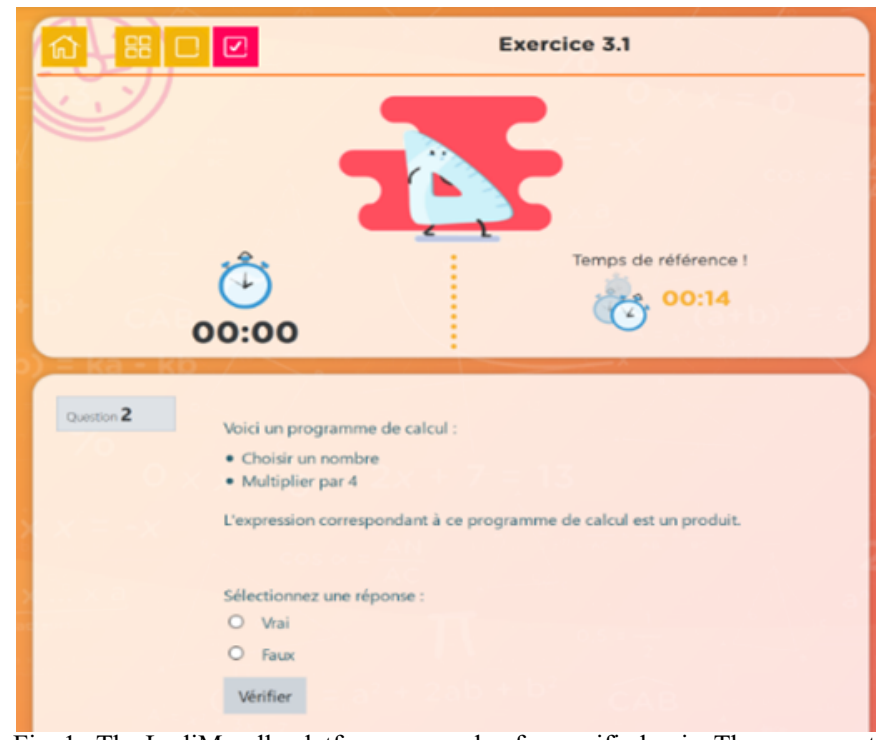

Fig. 1. The LudiMoodle platform: example of a gamified quiz. The upper part shows a timer, while the lower part contains a quiz question 
$>$ REPLACE THIS LINE WITH YOUR MANUSCRIPT ID NUMBER (DOUBLE-CLICK HERE TO EDIT) $<$

\section{A. Learning Content}

We built the learning content using a co-design method with the participating teachers in order to remain as close as possible to their usual teaching practices. In total, ten lessons were designed to cover the topic of basic algebra (calcul litteral in French). Each lesson is composed of 4 to 10 quizzes.

\section{B. Game Elements}

Each of the six game elements designed should appeal to at least one of the different Hexad player types. It is important to note that neither the Disruptor nor the Philanthropist types were specifically targeted by one of our game elements. We made this choice to avoid increasing the number of game elements (restricting ourselves to six commonly used in the literature, and in frameworks such as [1]), as both these types generally form a minority [40].

\section{1) Avatar}

The Avatar game element showed a goblin-like character that explored different universes (a different universe for each lesson). As the learner progressed in a lesson, they would unlock a different piece of clothing or an item that the character was holding. There was one object to unlock per quiz (that was unlocked after the learner correctly answered at least $70 \%$ of the questions in the quiz). Game elements such as this are generally recommended for Free Spirits, as these Avatars provide them with a personalized representation of themselves [17].

\section{2) Badges}

The badges game element proposed three levels of badges per quiz. When the learners correctly resolved three different levels of questions in the quiz (generally $70-85-100 \%$ of each quiz), they would unlock a new level of badge (bronze-silvergold). An icon on the left-hand side showed how many badges the student unlocked for the current lesson. Badges are generally shown to be motivating for all users [41], but are normally particularly effective for Players and Achievers, as they represent clear-cut goals for them to achieve with attractive rewards [17].

\section{3) Progress}

This game element showed different colored spaceships that traveled from the earth to the moon. Each lesson launched a new spaceship, and if the learner completed at least $70 \%$ of the lesson, the spaceship would land on the moon. This game element should prove particularly interesting for the Achiever player type as, just like Badges, we have a clear goal [17].

\section{4) Ranking}

The learners assigned to this game element could compare themselves to a fictional class of learners. The Ranking game element showed a "race" where, as the learners answered questions correctly, they would progress in the race at the same pace as the other fictional learners. If they failed to answer a question correctly, they would fall back in the ranking. We calibrated the ranking system to ensure that a learner who completed at least $70 \%$ of a lesson would finish in the top $50 \%$ of the ranking to ensure they were not demotivated. As this game element allows learners to compare themselves to others, (even if fictional), it should be motivating for Socializers [17].

\section{5) Score}

Learners are awarded 1000 points for each correct answer they give. Each lesson had its own score counter, with a detailed view showing the number of points they scored for each quiz, so that learners could pinpoint the missing points. As this game element gives learners a clear representation of how well they are doing in the course and rewards them for performing better, it should prove attractive to Players [17].

\section{6) Timer}

This game element showed a timer for each quiz. Learners were asked to try and beat a "reference time" for each question. The reference times were calculated based on the times for their previous questions in the same quiz. Each time a learner beat their reference time, an animation changed, showing a character that ran faster and faster. Here, learners are challenged to beat themselves in a race, thus making the Timer attractive to Achievers [17].

TABLE I

PARTICIPANT INFORMATION

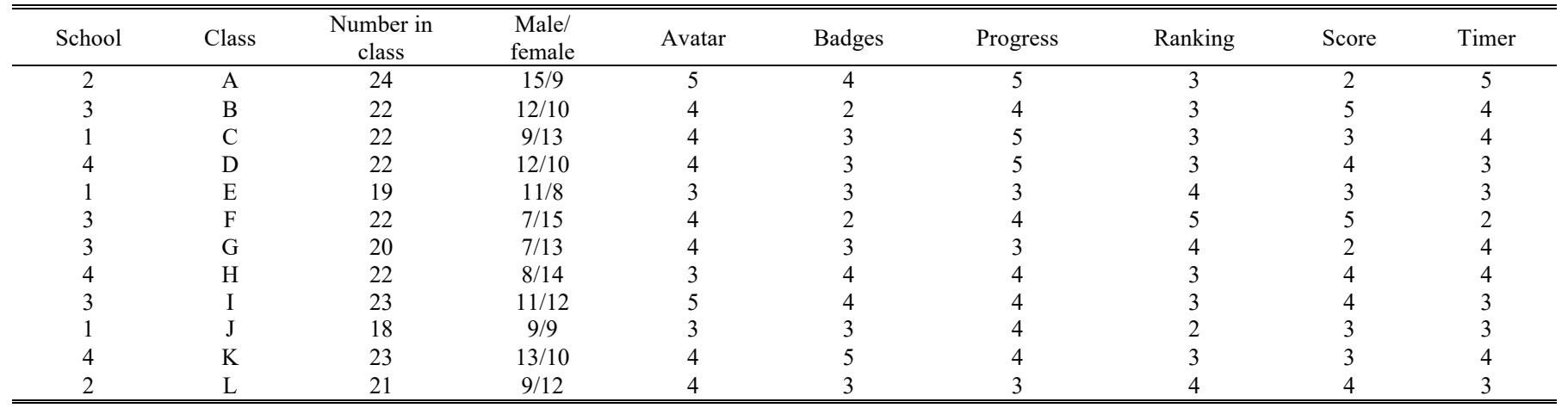

All participants were native french speakers aged between 14 to 15 years old. 
$>$ REPLACE THIS LINE WITH YOUR MANUSCRIPT ID NUMBER (DOUBLE-CLICK HERE TO EDIT) <

\section{Study Design}

\section{A. Participants}

A total of five teachers and 258 students (14 to 15 years old) in 12 classes (an average of 25 students per class), from four different secondary schools, participated in the study (see Table I). Teachers were involved in the co-design of the game elements and in the construction of the course content. Game elements were randomly distributed, while respecting parity between genders, classes, and colleges. We ensured that there was no class or gender effect at the outset. Learners were free to discuss the game elements they received.

\section{B. Material and Data}

\section{1) Motivated Behaviors}

Learner interactions with the learning environment were tracked using the Moodle data logging system. In order to determine learner-motivated behaviors, we distinguished learner-motivated behaviors that were different from normal and expected behaviors induced by the pedagogical scenario:

--Restarted Quiz Count: we identified the number of quizzes they retried after having completed them. Learners were required to correctly answer at least $70 \%$ of each quiz to access the next one. If a learner successfully completed a quiz and then retried to achieve more than $70 \%$, it showed that they were particularly engaged to achieve a higher result.

--Question Ratio: we looked at the question ratio of correct and incorrect answers given by the learners as a measure of their cognitive involvement in the task.

\section{2) Profile Questionnaires}

We used the motivation scale proposed by Vallerand et al. [36], inspired by SDT [20]. This scale, called the Academic Motivation Scale (AMS), is composed of 28 items subdivided into seven sub-scales, assessing, with a 5-point Likert-type scale, seven dimensions of motivation (three for intrinsic motivation (IM), three for extrinsic motivation (EM), and one for amotivation (AMOT), following a continuum of selfdetermination:

--Intrinsic Motivation for Knowledge, that is, performing an activity for the pleasure and satisfaction of doing something new: "I like learning new things."
--Intrinsic Motivation for Accomplishment, that is, performing an activity for the pleasure of overcoming a challenge: "I like to see that I am able to solve problems."

--Intrinsic Motivation for Stimulation, that is, performing an activity for fun or excitement: "I really like math."

--External Regulation, that is, performing an activity to gain some kind of external rewards: "I want to get a good grade."

--Introjected Regulation, that is, performing an activity to avoid shame or increase self-esteem: "I want to prove that I can do well in math."

--Identified Regulation, that is, performing an activity in order to achieve precise objectives: "I will be able to choose my future studies thanks to math."

--Amotivation, that is, the absence of intention to perform an activity: "I don't know why I went to math class; I feel like I'm wasting my time."

We identified the learner player profile using a translated version of the original Hexad questionnaire [17], which defines six player types, distributed along a continuum of "willing to play":

--Player, motivated by their personal success: "I like competitions where a prize can be won."

--Socializer, motivated by social contact: "Interacting with others is important to me."

--Free Spirit, motivated by creation and exploration: "It is important to me to follow my own path."

--Achiever, motivated by challenges: "I like overcoming obstacles."

--Philanthropist, whose goal is to help others: "It makes me happy if I am able to help others."

--Disruptor, motivated by change: "I like to provoke."

Some player profile types are correlated with some of the basic psychological needs described in the SDT: Player and Achiever profiles are positively correlated with the need for competence; Philanthropist and Socializer profiles are positively correlated with the need for relatedness; Free Spirit and Disruptor profiles are linked to the need for autonomy.

3) Procedure

The experiment was conducted over three consecutive

TABLE II

MOTIVATIONAL VARIATIONS IN TOTAL AND PER GAME ELEMENT (W VALUES)

\begin{tabular}{|c|c|c|c|c|c|c|c|c|}
\hline Game Element & & All & Avatar & Badges & Progress & Ranking & Score & Timer \\
\hline \multirow[t]{3}{*}{$\Delta$ Intrinsic motivations $(\Delta \mathrm{IM})$} & $\Delta$ Knowledge & -9.769 & -4.627 & -4.22 & -3.747 & -4.629 & -3.829 & -2.969 \\
\hline & $\Delta$ Accomplishment & -1.235 & -0.121 & -2.217 & -0.415 & -0.703 & -0.621 & -0.197 \\
\hline & $\Delta$ Stimulation & -1.261 & -0.414 & -1.278 & -0.019 & -1.882 & -0.763 & -0.33 \\
\hline \multirow[t]{3}{*}{$\Delta$ Extrinsic motivations $(\Delta \mathrm{EM})$} & $\Delta$ Identified reg. & -0.128 & -0.082 & -2.259 & -0.197 & -0.685 & -1.211 & -1.322 \\
\hline & $\Delta$ Introjected reg. & -0.659 & -0.54 & -1.917 & -0.534 & -0.354 & -0.209 & -0.809 \\
\hline & $\Delta$ External reg. & -6.209 & -2.976 & -3.363 & -4.007 & -1.448 & -0.83 & -2.536 \\
\hline$\Delta$ Amotivation $(\Delta$ AMOT $)$ & $\Delta$ Amotivation & 10.78 & 4.125 & 5.225 & 3.683 & 5.397 & 4.523 & 3.561 \\
\hline
\end{tabular}

Values in gray are not significant $(p>.05)$, values highlighted in light gray are significant $(p<.05)$, values highlighted in dark gray are highly significant $(p<.01)$, and values highlighted in black are very significant $(p<.001)$. 
$>$ REPLACE THIS LINE WITH YOUR MANUSCRIPT ID NUMBER (DOUBLE-CLICK HERE TO EDIT) <

weeks. Each lesson was conducted in the same way: 10 to 15 minutes of written notes (these notes were handed out to learners by the teachers to ensure that they had access to the same content), followed by 25 to 30 minutes for answering quizzes related to the lesson topic. The learners used an individual tablet to access the quizzes. Teachers answered technical questions asked by learners individually. Learners had to answer both the AMS and Hexad questionnaires at the beginning of the experiment (Pretest). At the end of the experiment (Posttest), they only had to answer the AMS questionnaire to be able to measure the variation in motivation.

TABLE III

MOtivational SCORES IN PRETEST AND POSTTEST

\begin{tabular}{llrll}
\hline \hline & \multicolumn{2}{c}{ Pretest } & \multicolumn{2}{c}{ Posttest } \\
& Average & $S D$ & Average & $S D$ \\
\hline MICO & 13.7907 & 3.55430 & 11.80 & 2.668 \\
MIAC & 15.4031 & 3.51875 & 15.19 & 3.686 \\
MIST & 11.9186 & 4.30604 & 11.75 & 4.062 \\
MEID & 14.8450 & 4.31980 & 14.80 & 4.028 \\
MEIN & 13.8992 & 3.58845 & 13.71 & 3.896 \\
MERE & 15.7248 & 3.41857 & 14.52 & 3.715 \\
AMOT & 6.92 & 3.314 & 9.76 & 2.856 \\
\hline \hline
\end{tabular}

\section{4) Statistical Tests}

To answer our first research question (RQ1), we compared the score of each motivation subscale between the pretest and the posttest, using a nonparametric Wilcoxon signed-rank test, as our data were not normally distributed. We choose to indicate whether the normalized $\mathrm{W}$ test is significant at $.05, .01$, and .001 , instead of the familywise error rate normally used for the parametric test (see Table II). Motivational scores figure in Table III.

To answer our second research question (RQ2), we used the partial least squares path modeling (PLS PM) method [37] to calculate the influence between the learner profile, defined by the initial motivation scores and the player type scores, and both the variations in motivations and the number of motivated behaviors. PLS PM is a method of structural equation modeling used to estimate complex cause-effect relationship models with latent variables. It has already been used in research studying the effects of gamification on user motivation [18], [38]-[41]. This method provides us with an estimation of the extent of the influence of an input value on an output value. As this is a statistical evaluation, we use the calculated $p$-value to determine the validity of the given influences. Our model is illustrated in Fig. 2.

The inner model is represented by the independent variables relative to the scores of initial motivations and player profiles, which, when grouped together (only for motivations), allow measurement of latent variables (IM, EM, AMOT). For example, the three intrinsic motivation scores: Knowledge, Accomplishment, and Stimulation were linked to create a general initial Intrinsic Motivation construct (IM). The outer

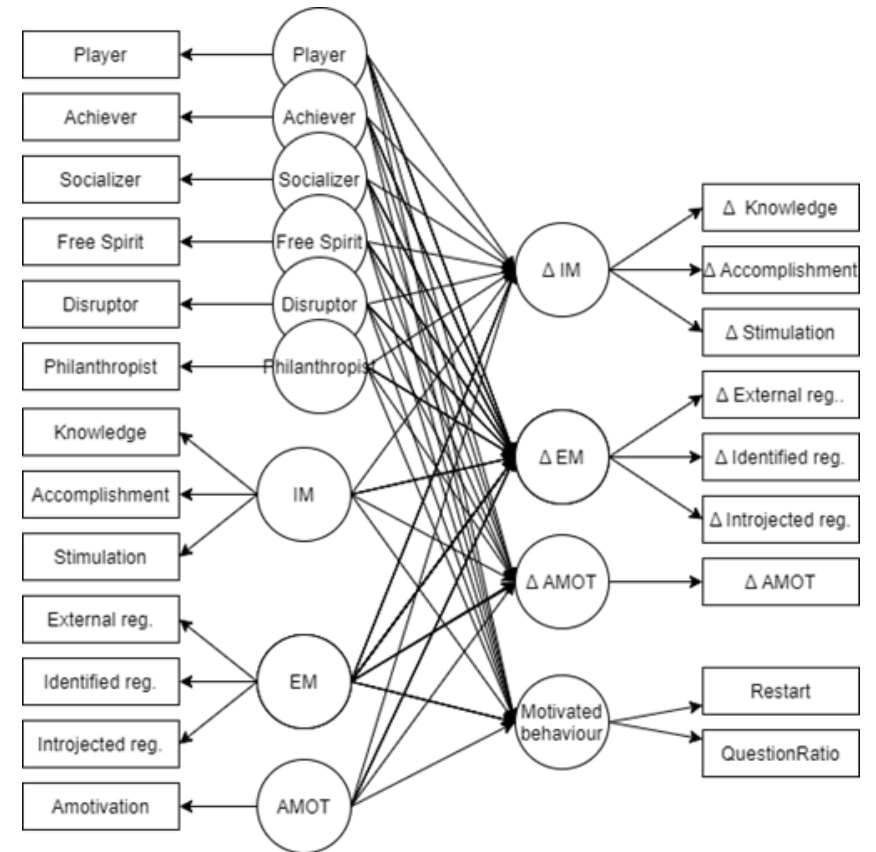

Fig. 2. Partial least squares path modeling analysis diagram. In rectangle borders the outer model, and in circle borders the inner model. On the left: the initial profile values of participants (i.e., Hexad profile, initial motivation for mathematics). On the right the observed outcomes (i.e., motivational variations and motivated behaviors)

model is represented by the dependent variables relative to the variations in scores of motivations between pre and posttest (which, when grouped together, allow measurement of latent variables, $\Delta \mathrm{IM}, \Delta \mathrm{EM}, \Delta \mathrm{AMOT}$ ), and the "motivated behavior" latent variable (which groups the "restart" and "questions ratio" variables). We verified the reliability, the internal consistency, the convergent validity of all our latent variables in Table V, and the coefficient of determination, $R^{2}$, for the latent variables of the outer model in Table IV.

\section{REsUlts}

\section{A. RQ1. How does Gamification Affect Learner Motivation?}

Our first analysis, using a nonparametric Wilcoxon signedrank test, was applied considering all learners. It shows a significant decrease in intrinsic motivation to knowledge and in external motivation to regulation, as well as a significant increase in amotivation, at the end of the experimentation (see TABLE IV R SQUARED VALUES

\begin{tabular}{ll}
\hline \hline \multicolumn{1}{c}{ Dependent Variables } & $\mathrm{R}^{2}$ \\
\hline$\Delta \mathrm{IM}$ & .343 \\
$\Delta \mathrm{EM}$ & .12 \\
$\Delta$ AMOT & .451 \\
Motivated Behaviors & .026 \\
\hline \hline
\end{tabular}

Calculated for each dependent variable and showing the influence of both the Hexad profile and the initial motivation on the final values of each of these variables.

Table II). 
$>$ REPLACE THIS LINE WITH YOUR MANUSCRIPT ID NUMBER (DOUBLE-CLICK HERE TO EDIT) <

We then investigated the variations in motivation according to the game elements used, performing a nonparametric Wilcoxon test. These analyses confirmed the results obtained considering all game elements: there is a decrease in motivation for all game elements, nonsignificant for the Ranking and Score game elements. For those elements, we do not notice any significant decrease in external regulation. Finally, we observed a decrease in intrinsic motivation for accomplishment and identified regulation with the badges game element (see Table II).

We also noted significant differences in motivated behaviors, depending on the game elements received. Regarding the question ratio, the results highlight a significant difference $(\mathrm{p}=$ $.04<.05$ ) between learners who used a Timer and those who received Badges, with a higher ratio of correct answers for Badges (see Fig. 3(a)).

Concerning the restarted quiz count, we noted that learners who used a Timer restarted significantly less often than learners who received the Progress, Ranking or Score game elements (see Fig. 3(b)).

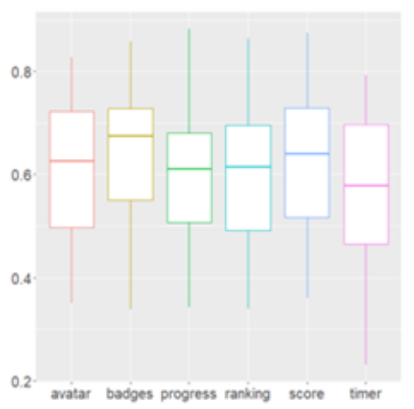

(a)

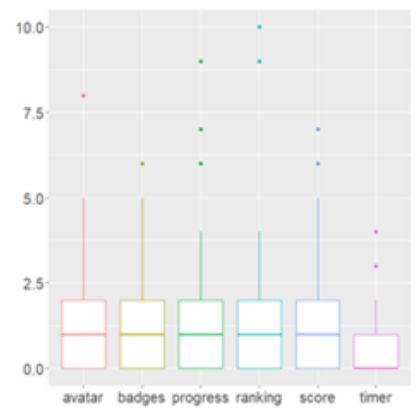

(b)
Fig. 3. Distributions for the motivated behavior metrics per game element. (a) Average question ratio. (b) Average restarted quiz count.

\section{B. RQ2. What Learner Characteristics Influence how Each Game Element Impacts Their Motivation?}

1) PLS Model

We performed a PLS PM in order to examine the influence of the "initial motivation" and "player profile" factors on the motivational variations and motivated behaviors during the experiment. The Path model used is described in Section IV. Based on the PLS Path analysis, we noted the importance of taking into account the initial motivations and the learner player profile, as $34.3 \%$ of the variation in intrinsic motivation, $12 \%$ of the variation in extrinsic motivation, and $45.1 \%$ of the variation in amotivation, could be accounted for by the level of initial motivations and the learner player profile (see Table IV). We also noted that the input variables only account for $2.6 \%$ of the motivated behavior of the learners. We wanted to know the weight of each of these input variables in these final variations. We generated T-statistics to test the significance of both the inner and the outer model (see Table V), using a bootstrapping method [42].

TABLE V

RESULTS SUMMARY FOR OUR REFLEXIVE INNER AND OUTER MODELS

\begin{tabular}{|c|c|c|c|c|c|}
\hline Latent variables & Indicators & Loadings & Composite reliability & AVE & Rho A \\
\hline \multirow[t]{3}{*}{ Init IM } & Init Knowledge & .922 & .919 & $.791>.5$ & $.868>.7$ \\
\hline & Init Accomplishment & .851 & & & \\
\hline & Init Stimulation & .893 & & & \\
\hline \multirow[t]{3}{*}{$\Delta \mathrm{IM}$} & $\Delta$ Knowledge & .874 & .803 & $.580>.5$ & $.760>.7$ \\
\hline & $\Delta$ Accomplishment & .639 & & & \\
\hline & $\Delta$ Stimulation & .752 & & & \\
\hline \multirow[t]{3}{*}{ Init EM } & Init Identified reg. & .770 & .818 & $.603>.5$ & $.705>.7$ \\
\hline & Init Introjected reg. & .878 & & & \\
\hline & Init External reg. & .688 & & & \\
\hline \multirow[t]{3}{*}{$\Delta \mathrm{EM}$} & $\Delta$ Identified reg. & .679 & .795 & $.566>.5$ & $.635<.7$ \\
\hline & $\Delta$ Introjected reg. & .842 & & & \\
\hline & $\Delta$ External reg. & .725 & & & \\
\hline
\end{tabular}

Indicator reliability > .70; internal consistency reliability $>.70$ or .60 in an exploratory research; convergent validity $>.50$. 
$>$ REPLACE THIS LINE WITH YOUR MANUSCRIPT ID NUMBER (DOUBLE-CLICK HERE TO EDIT) $<$

\section{2) Effect of Initial Motivation on The Variation in Motivation}

Results (see Table VI) show a negative influence of the level of amotivation on the variation in amotivation. Moreover, the initial level of amotivation has a positive influence on the variation in intrinsic motivation. These two influences mean that the more amotivated a learner is initially, the less amotivated and the more motivated intrinsically they are at the end. We also notice that the level of initial intrinsic motivation

\section{4) Different Effects Depending on The Game Element}

For each game element used, we ran a PLS path analysis to determine the influence of the initial motivation scores and the learner Hexad player profile on both the variations in each motivation type and the motivated behavior markers (see Fig. 2). These analyses were performed using groups of learners that had the same game element when using the learning environment. This enabled us to acquire a more precise insight into how each of these game elements impacted the variations

TABLE VI

RESUlTS OF THE PLS PATH ANALYSIS USING THE ENTIRE LEARNER BASE

\begin{tabular}{|c|c|c|c|c|c|c|c|c|c|}
\hline & Init IM & Init EM & Init AMOT & Achiever & Player & Socializer & Free spirit & Disruptor & Philanthropist \\
\hline$\Delta \mathrm{IM}$ & -.698 & .098 & .156 & .247 & .193 & -.048 & -.006 & -.022 & -.064 \\
\hline$\Delta \mathrm{EM}$ & .041 & -.528 & .004 & .230 & .132 & -.025 & .174 & -.119 & -.074 \\
\hline Motivated Behavior & .107 & -.044 & -.014 & .193 & -.015 & -.129 & -.003 & .048 & .104 \\
\hline
\end{tabular}

Values in gray are not significant $(p>.05)$, values highlighted in light gray are significant $(p<.05)$, values highlighted in dark gray are highly significant $(p<$ $.01)$, and values highlighted in black are very significant $(p<.001)$

negatively influenced the variation in intrinsic motivation, and that the level of extrinsic motivation influenced negatively the variation in extrinsic motivation. This means that the more a learner is intrinsically or extrinsically motivated initially, the less motivated they are at the end for this motivation type.

\section{3) Effect of Player Profile on The Variation in Motivation}

Results (see Table VII) show contrasting effects depending on the player profile considered. We noted a significant increase in both intrinsic and extrinsic motivation for the Achiever, with a significant decrease in amotivation and a positive influence on motivated behaviors. The Player score in motivation types and which player profile types contributed to these variations, even if these results deserve to be consolidated with larger samples.

--Avatar: We found four statistically significant influences (see Table VII) for learners with the Avatar game element. Learner initial amotivation score positively influenced the variation in their intrinsic motivation, and negatively the variation in their amotivation. The Player score also positively influenced the variation in intrinsic motivation, while the Socializer score only negatively influenced this same variation in motivation.

TABLE VII

PLS PATH COEFFICIENTS OBSERVED FOR LEARNERS WHO RECEIVED THE AVATAR GAME ELEMENT

\begin{tabular}{|c|c|c|c|c|c|c|c|c|c|}
\hline & Init IM & Init EM & Init AMOT & Achiever & Player & Socializer & Free spirit & Disruptor & Philanthropist \\
\hline$\Delta \mathrm{IM}$ & -.407 & -.029 & .366 & .145 & .478 & -.372 & -.049 & .006 & .183 \\
\hline$\Delta \mathrm{EM}$ & & -.390 & .100 & -.056 & .296 & -.363 & -.018 & -.028 & -.091 \\
\hline Motivated Behavior & & .055 & .179 & -.041 & -.186 & -.089 & -.008 & & .316 \\
\hline
\end{tabular}

Values in gray are not significant $(p>.05)$, values highlighted in light gray are significant $(p<.05)$, values highlighted in dark gray are highly significant $(p$ $<.01)$, and values highlighted in black are very significant $(p<.001)$

seems to increase both intrinsic motivation and extrinsic motivation. The Free Spirit score also increases extrinsic motivation. Finally, the Socializer, Disruptor, and Philanthropist scores show no significant influence.

--Badges: We only found two statistically significant influences for learners who used badges (see Table VIII).

TABLE VIII

PLS PATH COEFFICIENTS OBSERVED FOR LEARNERS WHO RECEIVED THE BADGES GAME ELEMENT

\begin{tabular}{|c|c|c|c|c|c|c|c|c|c|}
\hline & Init IM & Init EM & Init AMOT & Achiever & Player & Socializer & Free spirit & Disruptor & Philanthropist \\
\hline$\Delta \mathrm{IM}$ & -.337 & -.099 & .085 & -.007 & .308 & -.056 & -.308 & -.016 & .091 \\
\hline$\Delta \mathrm{EM}$ & .292 & -.408 & -.095 & -.160 & .095 & -.206 & -.198 & -.181 & .149 \\
\hline$\triangle \mathrm{AMOT}$ & .497 & -.111 & -.361 & -.419 & & .036 & .199 & -.013 & -.036 \\
\hline Motivated Behavior & -.544 & -.039 & -.302 & .097 & -.053 & .014 & .136 & .505 & \\
\hline
\end{tabular}

Values in gray are not significant $(p>.05)$, values highlighted in light gray are significant $(p<.05)$, values highlighted in dark gray are highly significant $(p$ $<.01)$, and values highlighted in black are very significant $(p<.001)$ 
$>$ REPLACE THIS LINE WITH YOUR MANUSCRIPT ID NUMBER (DOUBLE-CLICK HERE TO EDIT) <

Learner initial intrinsic motivation negatively influenced the motivated behaviors, whereas their Disruptor score positively influenced these behaviors.

--Progress: We observe three significant influences for learners who used the Progress game element (see Table IX). Each of the initial motivations negatively influenced the variation in the same motivation type. observed. Initial extrinsic motivation negatively influenced both the variation in extrinsic motivation and the motivated behaviors. Initial amotivation negatively influenced the variations in intrinsic motivation and amotivation, as well as the motivated behaviors observed. For the player profile, the Socializer score positively influenced the variation in extrinsic motivation and the Disruptor score had a similar effect on the variation in amotivation. The Philanthropist score negatively TABLE IX

PLS PATH COEFFICIENTS OBSERVED FOR LEARNERS WHO RECEIVED THE PROGRESS GAME ELEMENT

\begin{tabular}{|c|c|c|c|c|c|c|c|c|c|}
\hline & Init IM & Init EM & Init AMOT & Achiever & Player & Socializer & Free spirit & Disruptor & Philanthropist \\
\hline$\Delta \mathrm{IM}$ & -.680 & .229 & -1.108 & -.048 & .178 & -.015 & -.115 & .374 & -.028 \\
\hline$\Delta \mathrm{EM}$ & .092 & -.574 & -.108 & .234 & .295 & .068 & .112 & -.014 & -.207 \\
\hline Motivated Behavior & .018 & & -.076 & .425 & -.018 & -.124 & .022 & -.063 & .132 \\
\hline
\end{tabular}

Values in gray are not significant $(p>.05)$, values highlighted in light gray are significant $(p<.05)$, values highlighted in dark gray are highly significant $(p<$ $.01)$, and values highlighted in black are very significant $(p<.001)$.

influenced the motivated behaviors observed.

--Ranking: Results show many significant influences for the Ranking element (see Table X). Initial intrinsic motivation negatively influenced the variation in intrinsic motivation, and positively the variation in amotivation. Initial extrinsic motivation negatively influenced the variation in extrinsic motivation. For the Achiever profile, Score negatively influenced the variation in amotivation. The Free Spirit score positively influenced the variation in extrinsic motivation,
--Timer: We found eight significant influences for this game element (see Table XII). Initial intrinsic motivation negatively influenced the variation in intrinsic motivation, while initial amotivation negatively influenced the variation in amotivation. For the player profile, the Achiever score positively influenced the variation in intrinsic and extrinsic motivation, as well as the motivated behaviors generated. The Free Spirit score positively influenced the variation in extrinsic motivation. Finally, the Philanthropist score negatively influenced the variations in both

TABLE X

PLS PATH COEFFICIENTS OBSERVED FOR LEARNERS WHO RECEIVED THE RANKING GAME ELEMENT

\begin{tabular}{|c|c|c|c|c|c|c|c|c|c|}
\hline & Init IM & Init $\mathrm{EM}$ & Init AMOT & Achiever & Player & Socializer & Free spirit & Disruptor & Philanthropist \\
\hline$\Delta \mathrm{IM}$ & -.466 & -.143 & .248 & .150 & .018 & -.001 & .055 & -.039 & -.140 \\
\hline$\Delta \mathrm{EM}$ & .319 & -.609 & .108 & .122 & .116 & .120 & .323 & -.396 & -.172 \\
\hline Motivated Behavior & -.016 & -.125 & .006 & .225 & & -.199 & .114 & .263 & -.036 \\
\hline
\end{tabular}

Values in gray are not significant $(p>.05)$, values highlighted in light gray are significant $(p<.05)$, values highlighted in dark gray are highly significant $(p<$ $.01)$, and values highlighted in black are very significant $(p<.001)$.

whereas the Disruptor score negatively influenced it. The latter intrinsic and extrinsic motivations. score also positively influenced the variation in amotivation.

--Score: Score is the game element that showed the most statistically significant influences (see Table XI). Initial intrinsic motivation negatively influenced the variation in intrinsic motivation, and positively the motivated behaviors

TABLE XI

PLS PATH COEFFICIENTS OBSERVED FOR LEARNERS WHO RECEIVED THE SCORE GAME ELEMENT

\begin{tabular}{|c|c|c|c|c|c|c|c|c|c|}
\hline & Init IM & Init EM & Init AMOT & Achiever & Player & Socializer & Free spirit & Disruptor & Philanthropist \\
\hline$\Delta \mathrm{IM}$ & -.909 & -.098 & -.615 & 261 & -.202 & .208 & -.032 & .120 & -.183 \\
\hline$\Delta \mathrm{EM}$ & .304 & -1.032 & -.302 & .250 & .040 & .465 & -.030 & -.289 & -.202 \\
\hline$\Delta$ AMOT & -.342 & .156 & -.752 & .041 & .208 & -.005 & -.058 & .490 & .015 \\
\hline Motivated Behavior & .786 & -.721 & -.423 & .071 & -.127 & .131 & .168 & .204 & -.631 \\
\hline
\end{tabular}

Values in gray are not significant $(p>.05)$, values highlighted in light gray are significant $(p<.05)$, values highlighted in dark gray are highly significant $(p<$ $.01)$, and values highlighted in black are very significant $(p<.001)$ 
$>$ REPLACE THIS LINE WITH YOUR MANUSCRIPT ID NUMBER (DOUBLE-CLICK HERE TO EDIT) <

TABLE XII

PLS PATH COEFFICIENTS OBSERVED FOR LEARNERS WHO RECEIVED THE TIMER GAME ELEMENT

\begin{tabular}{|c|c|c|c|c|c|c|c|c|c|}
\hline & Init IM & Init EM & Init AMOT & Achiever & Player & Socializer & Free spirit & Disruptor & Philanthropist \\
\hline$\Delta \mathrm{IM}$ & -.571 & -.101 & .325 & .639 & .104 & .180 & -.170 & -.228 & -.366 \\
\hline$\Delta \mathrm{EM}$ & -.421 & & .288 & .689 & -.015 & .065 & .318 & -.013 & -.407 \\
\hline$\Delta \mathrm{AMOT}$ & -.325 & -.140 & -1.112 & .097 & .056 & .124 & .073 & .011 & -.226 \\
\hline Motivated Behavior & .120 & & .287 & .749 & & .011 & -.332 & -.222 & \\
\hline
\end{tabular}

Values in gray are not significant $(p>.05)$, values highlighted in light gray are significant $(p<.05)$, values highlighted in dark gray are highly significant $(p$ $<.01)$, and values highlighted in black are very significant $(p<.001)$.

\section{DISCUSSION}

\section{A. Gamification Approach that Generally Demotivates}

This research allows us to draw meaningful conclusions regarding the impact of gamification on learner motivation. We first showed that randomly assigned game elements generally result in a decrease in motivation. We found that the external regulation of learners was lower after the experiment. One possible explanation is that learners motivated by their mathematic grades were frustrated that they did not receive any grades for the completed quizzes completed during the experiment (a choice made by the teachers for the experiment). We also noticed a general decrease in intrinsic motivation for knowledge, which raises questions about the perceived value of the learning activity. It seems that learners perceived the exercises more as a game than as a serious learning activity, which echoes the findings by Barata et al. [16]. This may also be due to the duration of the study, as teachers testified that some learners were a little bored after ten quiz sessions.

We then showed that learner amotivation generally increased for all learners regardless of the game element they used, meaning that they found fewer reasons to do mathematic. This result is similar to that found in a previous study we conducted with a gamified learning environment dedicated to learning French grammar [4]. Learners provided with game elements that were not adapted to their player profile showed higher levels of amotivation. This result could reflect one of the main effects of the learning activity itself, merely moderated by gamification.

Regardless of the game element used, we noticed a decrease in intrinsic motivation for knowledge and external regulation, except for learners who used the Ranking and the Score game elements. This may be due to the fact that these game elements closely emulated the feeling of receiving a grade for their work (i.e., the Score gave a numerical rating of their performance, while the Ranking showed them if they were performing better than others). With Badges, we observed that more types of motivation were negatively impacted compared to other game elements (intrinsic motivation for accomplishment and identified regulation). This corroborates the results presented by Hanus et al. [43], which suggest that Badges and other rewards are considered as controlling rewards, since they encourage action but constrain it to the objectives proposed by Badges. This perception could degrade learner intrinsic motivation.

\section{B. More Contrasting Effects Depending on Learner Profile}

We show in Sections VI-B-2 and VI-B-3 that these general effects on learner motivation vary depending on their initial motivation and player profile.

\section{1) The Influence of Initial Motivation}

The negative influence between each type of motivation on the variation in this motivation (e.g., initial intrinsic motivation negatively influences the variation in intrinsic motivation) highlighted the fact that gamification motivated learners who were less motivated initially. Learners who were initially intrinsically and extrinsically demotivated, were more motivated after the experimentation, while those who were more intrinsically and extrinsically motivated, were those most demotivated at the end. This result has great implications for a gamification approach not adapted to learners. Such an approach should be used with extreme caution depending on learner initial motivation for the discipline.

The analysis performed per game element (see Section VI.B.4) allowed us to further investigate these results and to show that game elements affect learners differently.

Among the positive influences, we noted that the Avatar game element increased intrinsic motivation and decreased the amotivation of the more amotivated learners. This result could be accounted for by an increase in the satisfaction of their need for social relatedness [20], as shown by Sailer et al. [23]. The Progress game element also decreases the amotivation of the most amotivated learners. This could be accounted for by an increase in the feeling of competence from this game element [20], [44]. The Score game element has a positive influence on the variation in motivated behaviors of intrinsically motivated learners, which could also be accounted for by a desire to do better and to feel more competent. The fact that the Score game element is, in this study, a non-controlling reward (learners have the choice of restarting the exercise or not), contributes to this increase in their intrinsic motivation [45]. Lastly, the more amotivated learners, who received the Timer game element, saw their amotivation decrease, suggesting once again that this performance incentive was perceived more as an affirmation of their need for competence [23], [45].

However, we found that certain game elements degraded the motivation of some learners, a fact also observed when considering the learners as an entire group. Learners with a high level of intrinsic motivation who used the Badges game element, experienced a decrease in their motivated behaviors. This could be accounted for by the controlling nature of this 
game element [43]. The Progress and Ranking game elements degraded the levels of intrinsic and extrinsic motivation of learners who had high initial levels of these motivations. These results suggest that game elements that foster social comparison [48]-[49] could be detrimental to learner motivation. The Score game element also decreased the motivated behaviors of the most amotivated learners, as well as their intrinsic motivation. Learners may have perceived this game element more as negative feedback [48], confronting them with their own difficulties in mathematic. Finally, learners initially intrinsically motivated to do mathematic, who received the Timer, experienced a decrease in their intrinsic motivation. This game element may have generated stress among the most motivated learners, a fact that was also reported by teachers following the experiment. This result is common with many gamification studies that show Timers as stressful for learners [40], [50].

To conclude, all types of initial motivation have an influence on the variation in motivation regardless of the game element used. These influences are mostly negative, meaning that the more motivated learners are, the less they will be motivated. However, the opposite is also true: the less motivated learners are, the more motivated they will become. Only the variation in amotivation and motivated behaviors are positively impacted when using Avatar, Progress, Timer or Score. For the Avatar, we assume that learners regarded the various items that they could collect for their Avatar as a set of fixed goals, which upon completion, satisfied both their needs for autonomy and for competence (which explains the increase in their motivation [21]). Progression, as an informational feedback, decreases the amotivation of the most amotivated, which can be justified by an increase in their feeling of competence [20]-[21]. Score would have acted as a non-controlling reward since it reduced the amotivation of the most amotivated. Learners could repeat exercises to improve their score if they wished. Therefore, they were not penalized by a score that might interfere with the continuation of the exercise [20]. Finally, the Timer decreased the amotivation of the most amotivated and increased their other motivations (intrinsic and extrinsic). It acted as an incentive for performance, which allowed the most amotivated learners to satisfy their need for competence, while giving them more pleasure [20], [44].

Based on these findings, we can conclude that game elements do not have the same potential to affect learner motivation according to their level of initial motivation, and thus that these initial motivations must be considered if we do not want gamification to be detrimental to learners. It is therefore necessary to design gamification approaches that take into account not only the learner player profile but also their interest in the subject (i.e., initial motivation). Future research should be conducted to investigate adaptation models that can combine these two types of profile to offer effective adaptation [51].

\section{2) The Influence of Initial Player Types}

When looking at learner player profile, the most impactful game elements vary considerably. The Timer had the greatest impact, involving an increase in both the intrinsic and extrinsic motivations for Achiever and Free Spirit learners. However, for Philanthropists, this game element had the opposite effect, generally demotivating them. These findings nuance the results obtained in the study conducted by Hallifax et al. [41] independently from a specific domain and context where they conclude that Timers are generally less preferred and should be avoided. The Ranking game element came next and showed four influences. Learners with high Free Spirit scores gained in extrinsic motivation, while Achievers became less amotivated. As Achievers are motivated by competence [17], it is not surprising that the virtual challenge of the ranking system motivated them. Free Spirit learners possibly looked for a way to "stand out from the crowd" [17] and therefore tried to come first. However, learners with high Disruptor scores lost extrinsic motivation and gained in amotivation. This game element could have made them feel demotivated since such learners are looking to go against the rules and will not be challenged by the ranking system, which mainly highlights learners who follow the rules. For Score, we observe positive effects only on socializers with an increase in extrinsic motivation. Both Disruptors and Philanthropists had, respectively, an increase in their amotivation and a decrease in their motivated behaviors. This is not surprising, as scoring systems are generally not recommended for motivated learners [41], [50]. This finding for Socializers is coherent with the results obtained in [26] that noted that learners like to compare their scores with others. With the Avatar game element, we noted an increase in motivation for those with a high Player score, as well as a decrease for those with a high Socializer score. Being able to develop their Avatar based on their correct answers was probably perceived by learners as a way to satisfy their personal success [23]. As there were no possibilities to show their Avatars to others, it is not surprising that a negative effect is observed for Socializers. We also found that Badges game elements encouraged motivated behaviors only for learners with a high Disruptor score. This is surprising as Badges are one of the most widely used game elements for gamification [25], [31], [41] and are generally accepted as motivating. Finally, no influences were observed for the Progress game element from the player profile scores. This result is contradictory with other studies, such as that conducted in [41] that shows influences depending on the Socializer and Disruptor player types. These differences may be due to the design of the game element itself. These findings show that five player types have an influence on the impact of game elements on learner motivation, and that all types of motivation and motivated behaviors are impacted, but in very different ways depending on the game elements involved. The Achiever and Disruptor player types have the most impact. These results allow us to provide some recommendations, described in the following section.

\section{3) Game Element Recommendations}

Based on all our findings, we can get a better understanding of how each game element influences the variations in learner 
motivation. This will allow us to make design recommendations based on how learner motivation should vary with a game element using initial motivation and Hexad type:

--We recommend Avatar for learners with a high initial amotivation or with a high player score. This is similar to the recommendation made by Tondello et al. [40], who suggest that the player type may also prefer collections. However, Avatar should be avoided for learners with high Socializer scores. Thisdiffers from the recommendations made by Orji et al. [38], who showed that the Socializer score has a positive influence on all game elements tested in a gameful health system. This could suggest that recommendations may vary depending on the context or the gamified task as shown in [41].

--Badges should be used for Disruptors and should be avoided for learners who are initially intrinsically motivated for mathematic. While Hallifax et al. [41] proposed that Badges be recommended for all users, they did not evaluate the influence of user initial motivation. This reinforces the need to consider this dimension when proposing such game elements.

--Progress is relevant for learners with a high initial amotivation, as it increases both their intrinsic and extrinsic motivations. Having clear goals or objectives is something that is also recommended in other studies [26]. Similar game elements are frequently recommended for various player types (never all of them though) in [38], [40], [41].

--Ranking works for high Free Spirit learners, but should be avoided for others, as learners with high intrinsic or extrinsic motivation, amotivation, or with high Achiever or Disruptor scores, will most likely feel demotivated by this game element. Leaderboards have already been shown to be demotivating and detrimental to learning in several studies [13], [41].

--Score can be recommended for learners with a high initial intrinsic motivation but who are also strong Socializers. However, as with ranking, this game element should be generally avoided. Learners with high extrinsic motivation, amotivation, or Disruptor or Philanthropist scores will find it demotivating. This is in line with other studies such as [41], [50] that show score game elements to be problematic. The positive influence of the Socializer type should be nuanced as Orji et al. [38] found positive influences for all game elements with Socializers.

--Last but not least, Timer will generally be motivating for learners with high initial amotivation, or high Achiever or Free Spirit scores. However, learners with strong initial intrinsic motivation, or Philanthropist scores might find this game element demotivating. These results are quite different from a previous study that shows that this game element motivates learners with high intrinsic motivation [49]. However, it is in line with other studies, such as that presented by Hallifax et al. [41], which concludes that Timers are generally to be avoided. Tondello et al. [40] showed that challenges work quite well for Achievers, and it is possible that Timers in our context provided enough challenge for Achievers.

\section{LIMITATIONS}

We identified a few limitations in our study that may affect the generalization of our results. First in line are the domain and the targeted users. While we focus specifically on secondary school level Algebra, results may vary with a different subject, with learners of another age and in another domain than education. Next, as pointed out by Lessel et al. [52], the effect of gamification widely varies for willing participants (i.e., participants performed better when they had a choice in using the game elements). As the learners in our study did not choose their gamification, this could have affected their motivation or behavior. Finally, as pointed out by Ooge et al. [53], the Hexad questionnaire may function sub optimally in a teenage population in languages other than English. This could potentially account for part of our results.

\section{CONCLUSION}

In this paper we presented the results from a large-scale study on how gamification affects learner motivation and motivated behaviors. Our study ran for close to six weeks in four different secondary schools in France. We analyzed the data used by 258 students from 12 different classes, from over ten specifically designed mathematic lessons, gamified using six different game elements. Our results show that, in general, gamification is more adapted to less motivated or amotivated learners, who do not perceive mathematic as interesting. Our results also highlight the necessity to adapt gamification not only based on a learner player profile as commonly acknowledged in the literature, but also based on their initial motivation. Both these factors are important for determining how a game element will affect learner motivation or behavior. Furthermore, the results obtained considering each game element separately highlight that they affect learner motivation differently. Gamification cannot be reduced to a behaviorist approach. Since the right game element is adapted to the right learner profile, it promotes self-determination. Care must be taken when proposing game elements to learners, as these may have contradictory effects depending on their profile.

These results open up new perspectives, such as an adaptation to the learner profile. Some authors propose a static adaptation, classifying individuals according to their profile type, prior to the activity, using questionnaires such as BrainHex [15], [41], [54], or Hexad [35], [40]. Others consider that play preferences can change during activity because, as Lazzaro [55] points out, the motivations to play are not fixed and can change in the course of the day. Our future works will be directed toward the analysis of learner engagement based on their interaction traces with the learning environment in order to recommend dynamically adapted game elements in situation [29].

\section{REFERENCES}

[1] S. Deterding, "The Lens of Intrinsic Skill Atoms: A Method for Gameful Design," Human-Computer Interaction, vol. 30, no. 3-4, pp. 294-335, May. 2015, doi: 10.1080/07370024.2014.993471.

[2] R. N. Landers and A. K. Landers, "An Empirical Test of the Theory of Gamified Learning: The Effect of Leaderboards on Time-on-Task and 
$>$ REPLACE THIS LINE WITH YOUR MANUSCRIPT ID NUMBER (DOUBLE-CLICK HERE TO EDIT) <

Academic Performance," Simulation \& Gaming, vol. 45, no. 6, pp. 769785, Dec. 2014, doi: 10.1177/1046878114563662.

[3] P. Denny, F. McDonald, R. Empson, P. Kelly, and A. Petersen, "Empirical Support for a Causal Relationship Between Gamification and Learning Outcomes," in Proc. 2018 CHI Conference on Human Factors in Computing Systems, (CHI'18), Montreal, QC, Canada, April 21-26, 2018, 2018, paper no. 311. doi: 10.1145/3173574.3173885.

[4] É. Lavoué, B. Monterrat, M. Desmarais and S. George, "Adaptive Gamification for Learning Environments," in IEEE Transactions on Learning Technologies, vol. 12, no. 1, pp. 16-28, 1 Jan.-March 2019, doi: 10.1109/TLT.2018.2823710.

[5] T. Lehto and H. Oinas-Kukkonen, "Persuasive features in web-based alcohol and smoking interventions: A systematic review of the literature," J. Med. Internet Res., vol. 13, e46, Jul., 2011, doi: 10.2196/jmir.1559.

[6] Y. Jia, B. Xu, Y. Karanam, and S. Voida, "Personality-targeted gamification: A survey study on personality traits and motivational affordances," in Proc. 2016 CHI Conference on Human Factors in Computing Systems, (CHI'16), San Jose, USA, 2016, pp. 2001-2013. doi: $10.1145 / 2858036.2858515$

[7] D. R. Flatla, C. Gutwin, L. E. Nacke, S. Bateman, and R. L. Mandryk, "Calibration games: Making calibration tasks enjoyable by adding motivating game elements," in Proc. 24th Annu. ACM Symp. User Interface Software and Technology (UIST'11), Santa Barbara, CA, USA, Oct. 16-19, 2011, pp. 403-412, doi: 10.1145/2047196.2047248.

[8] C. Eickhoff, C. G. Harris, A. P. de Vries, and P. Srinivasan, "Quality through flow and immersion: Gamifying crowdsourced relevance assessments," in Proc. 35th Int. ACM SIGIR Conf. Research and Development in Information Retrieval (SIGIR'12), Portland, OR, USA, Aug.12-16, 2012, pp. 871-880. doi: 10.1145/2348283.2348400.

[9] F. Oprescu, C. Jones, and M. Katsikitis, "I PLAY AT WORK-Ten principles for transforming work processes through gamification," Frontiers psychol., vol. 5, 2014, Art. no 14, doi: 10.3389/fpsyg.2014.00014.

[10] K. M. Kapp, The gamification of learning and instruction: Game-based methods and strategies for training and education, Hoboken, NJ, USA: Wiley, 2012.

[11] K. M. Kapp, The gamification of learning and instruction fieldbook: Ideas into practice, Hoboken, NJ, USA: Wiley, 2013.

[12] L. Nacke and S. Deterding, "Editorial: The maturing of gamification research," Comput. Human Behav., vol. 71, pp. 450-454, Jun. 2017, doi: 10.1016/j.chb.2016.11.062.

[13] R. Landers, K. Bauer, and R. Callan, "Gamification of task performance with leaderboards: A goal setting experiment", Comput. Human Behav., vol. 71, pp. 508-515, Jun. 2017, doi: 10.1016/j.chb.2015.08.008.

[14] M. D. Hanus and J. Fox, "Source customization reduces psychological reactance to a persuasive message via user control and identity perceptions," J. Interact. Advertising, vol. 17, pp. 1-12, Feb. 2017, doi: 10.1080/15252019.2017.1287023.

[15] L. E. Nacke, C. Bateman, and R. L. Mandryk, "BrainHex: A neurobiological gamer typology survey", Entertainment Comput., vol. 5, issue 1, pp. 55-62, Jan. 2014, doi: 10.1016/j.entcom.2013.06.002.

[16] G. Barata, S. Gama, J. Jorge, and D. Gonalves, "Studying student differentiation in gamified education: A long-term study," Comput. Human Behav., vol. 71, pp. 550-585, Jun. 2017, doi: 10.1016/j.chb.2016.08.049

[17] A. C. Marczewski, Even Ninja Monkeys like to play, London, United Kingdom: Blurb Inc, 2015.

[18] R. Orji, L. E. Nacke, and C. DiMarco, "Towards personality-driven persuasive health games and gamified systems," in Proc. 2017 CHI Conference on Human Factors in Computing Systems, (CHI'17), May 2017, pp. 1015-1027, doi: 10.1145/3025453.3025577.

[19] L. Van Houdt, M. Millecamp, K. Verbert, and V. Vanden Abeele, "Disambiguating preferences for gamification strategies to motivate proenvironmental behaviour," in Proc. 2020 CHI Conf. on Comput.-Human Interact (CHI' 2020), New York, NY, USA, November, 2020, pp. 241253, doi: $10.1145 / 3410404.3414244$.

[20] E. L. Deci and R. M. Ryan, "The 'What' and 'Why' of goal pursuits: Human needs and the Self-Determination of behavior," Psychological Inquiry, vol. 11, no. 4, pp. 227-268, Oct. 2000, doi: 10.1207/S15327965PLI1104_01.

[21] S. Rigby and R. M. Ryan, Glued to games: How video games draw us, in and hold us Spellbound, ABC-CLIO, Santa Barbara, USA, 2011.
[22] J. Hamari, "Do badges increase user activity? A field experiment on the effects of gamification," Comput. Human Behav., vol. 71, pp. 469-478, Jun. 2017, doi: 10.1016/j.chb.2015.03.036.

[23] M. Sailer, J. U. Hense, S. K. Mayr, and H. Mandl, "How gamification motivates: An experimental study of the effects of specific game design elements on psychological need satisfaction," Comput. Human Behav., vol. 69, pp. 371-380, Apr. 2017, doi: 10.1016/j.chb.2016.12.033.

[24] M. Filsecker and D. T. Hickey, "A multilevel analysis of the effects of external rewards on elementary students' motivation, engagement and learning in an educational game," Comput. \& Educ., vol. 75, pp. 136-148, Jun. 2014, doi: 10.1016/j.compedu.2014.02.008.

[25] E. Kyewski and N. C. Krmer, "To gamify or not to gamify? An experimental field study of the influence of badges on motivation, activity, and performance in an online learning course," Comput. \& Educ., vol. 118, pp. 25-37, Mar. 2018, doi: 10.1016/j.compedu.2017.11.006.

[26] L. Ding, C. Kim, and M. Orey, "Studies of student engagement in gamified online discussions," Comput. \& Educ., vol. 115, pp. 126-142 Dec. 2017, doi: 10.1016/j.compedu.2017.06.016.

[27] Z. Zainuddin, "Students' learning performance and perceived motivation in gamified flipped-class instruction," Comput. \& Educ., vol. 126, pp. 7588, Nov. 2018, doi: 10.1016/j.compedu.2018.07.003.

[28] B. Monterrat, M. Desmarais, E. Lavoué, and S. George, "A player model for adaptive gamification in learning environments," Artif. Intell. in Educ., vol. 9112, pp. 297-306, Jun. 2015, doi: 10.1007/978-3-319-19773-9_30.

[29] T. Jagut, I. Botiki, and H.-J. So, "Examining competitive, collaborative and adaptive gamification in young learners' math learning," Comput. \& Educ., vol. 125, pp. 444-457, Oct. 2018, doi: 10.1016/j.compedu.2018.06.022.

[30] R. van Roy and B. Zaman, "Need-supporting gamification in education: An assessment of motivational effects over time," Comput. \& Educ., vol. 127, pp. 283-297, Dec. 2018, doi: 10.1016/j.compedu.2018.08.018.

[31] J. Koivisto and J. Hamari, "The rise of motivational information systems: A review of gamification research," Int. J. of Inf. Management, vol. 45, pp. 191-210, Apr. 2019, doi: 10.1016/j.ijinfomgt.2018.10.013.

[32] R. Orji, R. L. Mandryk, J. Vassileva, and K. M. Gerling, "Tailoring persuasive health games to gamer type," in: Proc. SIGCHI Conf. on Human Factors in Computing Syst., ACM, 2013, pp. 2467-2476, doi: $10.1145 / 2470654.2481341$

[33] F. Roosta, F. Taghiyareh, and M. Mosharraf, "Personalization of gamification-elements in an e-learning environment based on learners' motivation," in 2016 8th International Symp. on Telecomm. (IST), pp. 637642, doi: 10.1109/ISTEL.2016.7881899

[34] M. D. Kickmeier-Rust, E.-C. Hillemann, and D. Albert, "Gamification and smart feedback: Experiences with a primary school level math app," Int. $J$. Game-Based Learn., vol. 4, pp. 35-46, Feb. 2014, doi: 10.4018/ijgbl.2014070104.

[35] A. Mora, G. F. Tondello, L. E. Nacke and J. Arnedo-Moreno, "Effect of personalized gameful design on student engagement," 2018 IEEE Global Engineering Education Conf. (EDUCON), 2018, pp. 1925-1933, doi: 10.1109/EDUCON.2018.8363471.

[36] R. J. Vallerand, L. G. Pelletier, M. R. Blais, N. M. Briere, C. Senecal, and E. F. Vallieres, "The academic motivation scale: A measure of intrinsic, extrinsic, and amotivation in education, educational and psychological measurement," Educ. and Psychol. Meas., vol. 52, no. 4, pp. 1003-1017, Dec. 1992, doi: 10.1177/0013164492052004025.

[37] M. Sarstedt, C. M. Ringle, and J. F. Hair, Jr., "Partial least squares structural equation modeling," in Handbook of Market Research, C. Homburg, M. Klarmann, and A. E. Vomberg, Eds., Cham, Switzerland: Springer, doi: 10.1007/978-3-319-05542-8_15-1.

[38] R. Orji, G. F. Tondello, and L. E. Nacke, "Personalizing persuasive strategies in gameful systems to gamification user types," in Proc. 2018 CHI Conference on Human Factors in Computing Systems, April 2018, Paper no. 435, doi: 10.1145/3173574.3174009.

[39] R. Orji, J. Vassileva, and R. L. Mandryk, "Modeling the efficacy of persuasive strategies for different gamer types in serious games for health," User Model. and User-Adapted Interact., vol. 24, pp. 453-498, Jul. 2014, doi: 10.1007/s11257-014-9149-8.

[40] G. F. Tondello, R. R. Wehbe, L. Diamond, M. Busch, A. Marczewski, and L. E. Nacke, "The gamification user types hexad scale," in Proc. 2016 Annu. Symp. on Computer-Human Interaction in Play, Oct. 2016, pp. 229243. doi: $10.1145 / 2967934.2968082$.

[41] S. Hallifax, A. Serna, J.-C. Marty, G. Lavoué, and E. Lavoué, "Factors to consider for tailored gamification," in Proc. Annu. Symp. on ComputerHuman Interaction in Play, Sept. 2019, doi: 10.1145/3311350.3347167. 
$>$ REPLACE THIS LINE WITH YOUR MANUSCRIPT ID NUMBER (DOUBLE-CLICK HERE TO EDIT) <

[42] B. Efron and R. Tibshirani, An introduction to the bootstrap, Chapman \& Hall/CRC Monographs on Statist. \& Applied Probability, 1993.

[43] M. D. Hanus and J. Fox, "Assessing the effects of gamification in the classroom: A longitudinal study on intrinsic motivation, social comparison, satisfaction, effort, and academic performance," Comput. \& Educ., vol. 80, pp. 152-161, Jan. 2015, doi: 10.1016/j.compedu.2014.08.019.

[44] W. Peng, J.-H. Lin, K. A. Pfeiffer, and B. Winn, "Need satisfaction supportive game features as motivational determinants: An experimental study of a Self-Determination Theory guided exergame," Media Psychol., vol. 15, pp. 175-196, May. 2012, doi: 10.1080/15213269.2012.673850.

[45] E. L. Deci, R. Koestner, and R. M. Ryan, "Extrinsic rewards and intrinsic motivation in education: Reconsidered once again," Review Educ. Research, vol. 71, no. 1, pp. 1-27, Mar. 2001, doi: 10.3102/00346543071001001.

[46] L. Festinger, "A theory of social comparison processes," Human Relations, vol. $7, \quad$ pp. 117-140, Jul. 1954, doi: 10.1177/001872675400700202.

[47] G. Orosz, D. Farkas, and C. P. Roland-Levy, "Are competition and extrinsic motivation reliable predictors of academic cheating?," Frontiers in Psychol., vol. 4, article 87, Feb. 2013, doi: 10.3389/fpsyg.2013.00087.

[48] R. J. Vallerand and G. Reid, "On the causal effects of perceived competence on intrinsic motivation: A test of cognitive evaluation theory," J. Sport and Exercise Psychol., vol. 6, pp. 94-102, 1984, doi: 10.1123/JSP.6.1.94.

[49] J. Jang, J. J. Y. Park, and M. Y. Yi, "Gamification of online learning, in: Artificial Intelligence in Education," in Comput. Science, Springer Int. Publishing, pp. 646-649, Jun. 2015, doi: 10.1007/978-3-319-197739 92.

[50] Y. Attali and M. Arieli-Attali, "Gamification in assessment: Do points affect test performance?," Comput. \& Educ., vol. 83, pp. 57-63, Apr. 2015, doi: 10.1016/j.compedu.2014.12.012.

[51] S. Hallifax, E. Lavoué, and A. Serna, "To tailor or not to tailor gamification? An analysis of the impact of tailored game elements on learners' behaviours and motivation," in Artificial intellig. educ., 2020, pp. 216-227, doi: 10.1007/978-3-030-52237-7_18.

[52] P. Lessel, M. Altmeyer, L. V. Schmeer, and A. Krger, “"Enable or disable gamification?': Analyzing the impact of choice in a gamified image tagging task," in Proc. 2019 CHI Conf. Human Factors in Computing Syst. - CHI '19, May 2019, Paper no: 150, doi: 10.1145/3290605.3300380.

[53] B. Monterrat, E. Lavoué, and S. George, "Toward an adaptive gamification system for learning environments," Comput. Supported Educ., Springer, vol. 510, pp. 115-129, Dec. 2015, doi: 10.1007/978-3319-25768-6_8.

[54] J. Ooge, R. De Croon, K. Verbert, and V. Vanden Abeele, “Tailoring gamification for adolescents: A validation study of big five and Hexad in dutch," in Proc. 2020 Symp. on Comput.-Human Interact. in Play. Assoc. for Comput. Machinery, Nov. 2020, doi: 10.1145/3410404.3414267.

[55] N. Lazzaro, "Why we play games: Four keys to more emotion." In Proc. Game Developers Conference 2004. 


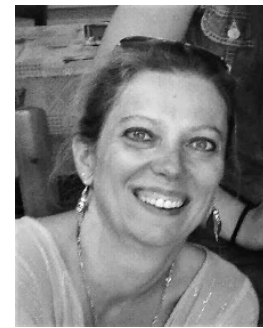

S. Reyssier was a Ph.D. student in educational sciences at the Education, Culture, and Policy (ECP) Lab, Lumière University Lyon 2, Lyon, France. She received the Ph.D. degree in Educational Sciences from the University of Lyon, in 2021, and is now a postdoctoral at the Institute for Science and Practice in Education and Training (ISPEF),

University of Lyon 2.

Her fields of specialization are gamification, selfdetermination, and the affordances of numeric environments in education. Her Ph.D. research examines teachers' perceptions of a numeric gamified environment for mathematics education that was co-designed with the teachers, as well as the impact of using the environment on learners' motivation.

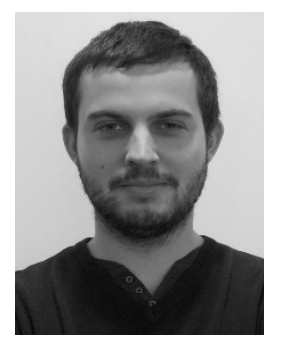

S. Hallifax was a Ph.D. in the Laboratory for Image Informatics and Information Systems (LIRIS) computer science laboratory, University of Lyon, Lyon, France. He is now a postdoctoral fellow in David R. Cheriton School of Computer Science, Faculty of Mathematics, University of Waterloo, Waterloo,

\section{CANADA.}

His main interests are gamification, user-behavior modeling, and user profiling. His Ph.D. research focuses on adaptive and gamified computer-based pedagogical resources.

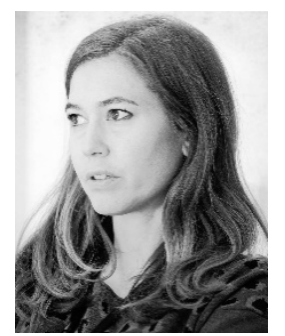

A. Serna is an associate professor with the National Institute of Applied Sciences of Lyon (INSA Lyon), Lyon, France.

Her interests lie at the confluence of computer science (human-computer interaction and usability/ergonomics) and cognitive science (cognitive modeling/user modeling). More specifically, she focuses on the design of novel interactive systems capable of adapting to the contexts of use, which become increasingly variable at runtime and unforeseeable at design time.

Her research is concerned mainly with two complementary aspects: user modeling and interaction with users.

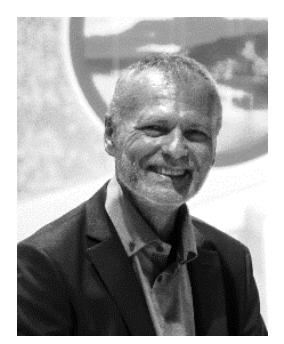

J.C. Marty is an associate professor with the LIRIS laboratory, University of Lyon, Lyon, France.

His research interests center around the observation of collaborative activities through the traces of those activities. The results of his research have applications in technology-enhanced learning, and in particular, game-based learning, environments. Dr. Marty is an active contributor to several projects in this field (Learning Adventure, Learning Games Factory, Serious Lab for Innovation, Pegase, Jen.lab, Janus). He organized an International School on Game-Based Learning in
France in June 2011, and is a member of several conference committees and journal editorial boards of journals in the field.

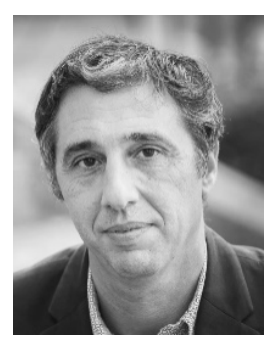

S. Simonian is a professor in educational sciences at the ISPEF, Lumière University Lyon 2, Lyon, France.

Until the $1^{\text {st }}$ September 2020, he was the director of the ISPEF, and he is now the director of the ECP Lab at the same university.

As a Specialist in educational technologies, his research focuses on learning scenarios and use cases, based on the concept on sociocultural affordance.

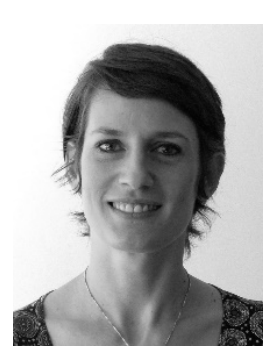

É. Lavoué is an associate professor of computer Science with the iaelyon School of Management, University of Lyon, Lyon, France and head of the Situated Interaction, Collaboration, Adaptation, and Learning (SICAL) research group within the LIRIS lab at the same university. She was a visiting professor at the ATLAS Lab, McGill University, Montréal, Canada, from January to August 2016.

Her research involves the design of learning environments to support learner self-regulation and engagement, and spans the fields of technology-enhanced learning, computer-supported collaborative learning, and human-computer interaction.

She has authored or co-authored over 90 publications, including journal articles, book chapters, and conference papers, in these areas. She served as general co-chair (CSCL'19), organizing chair (EC-TEL'16), program committee co-chair (EC-TEL'17), and program committee member for the EC-TEL, CSCL, LAK, and ITS international conferences, and is also member of the EC-TEL Steering Committee. 